
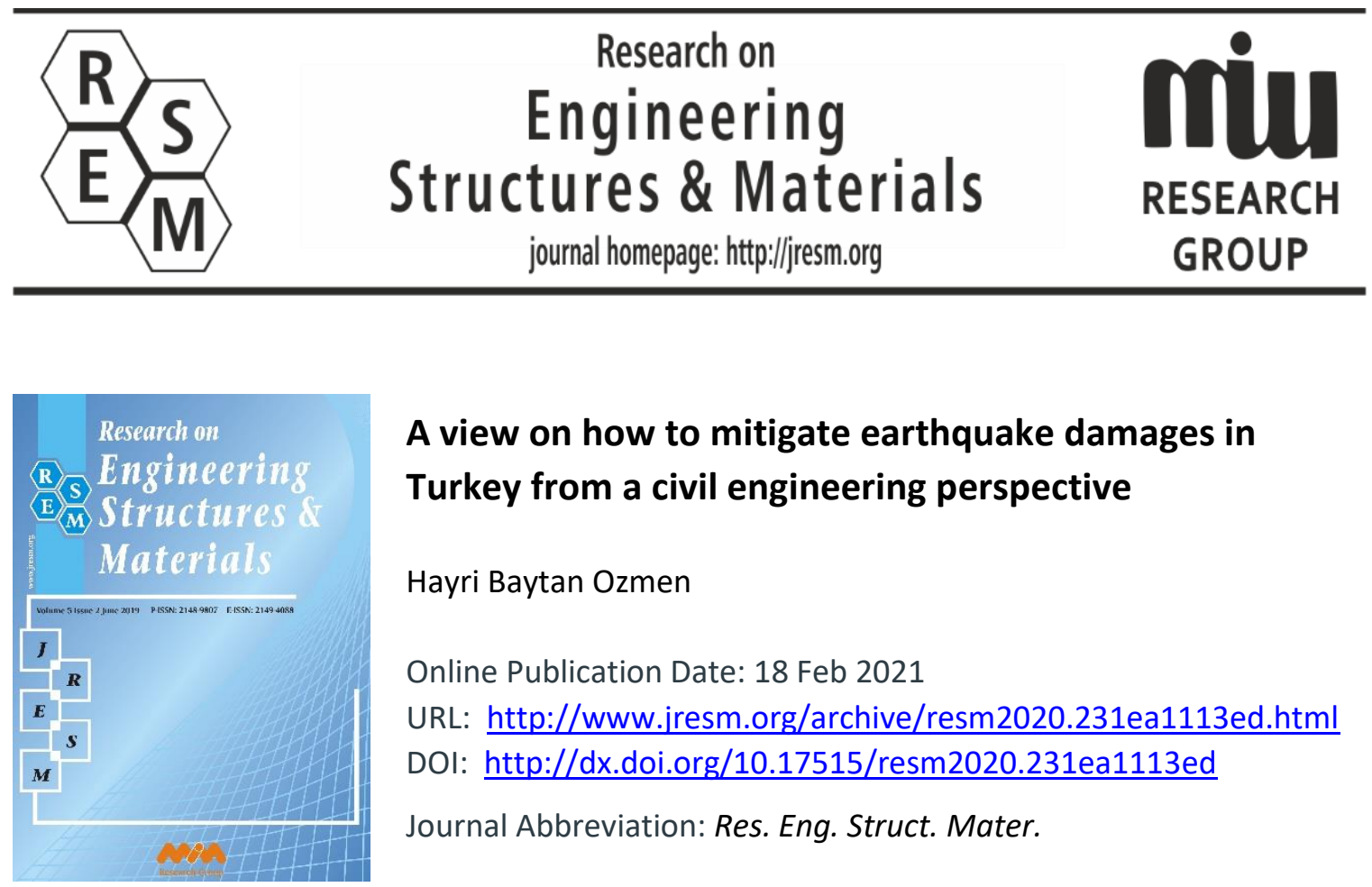

\title{
A view on how to mitigate earthquake damages in Turkey from a civil engineering perspective
}

Hayri Baytan Ozmen

Online Publication Date: 18 Feb 2021

URL: http://www.jresm.org/archive/resm2020.231ea1113ed.html

DOI: http://dx.doi.org/10.17515/resm2020.231ea1113ed

Journal Abbreviation: Res. Eng. Struct. Mater.

\section{To cite this article}

Ozmen H B. A view on how to mitigate earthquake damages in Turkey from a civil engineering perspective. Res. Eng. Struct. Mater., 2021; 7(1): 1-11.

\section{Disclaimer}

All the opinions and statements expressed in the papers are on the responsibility of author(s) and are not to be regarded as those of the journal of Research on Engineering Structures and Materials (RESM) organization or related parties. The publishers make no warranty, explicit or implied, or make any representation with respect to the contents of any article will be complete or accurate or up to date. The accuracy of any instructions, equations, or other information should be independently verified. The publisher and related parties shall not be liable for any loss, actions, claims, proceedings, demand or costs or damages whatsoever or howsoever caused arising directly or indirectly in connection with use of the information given in the journal or related means.

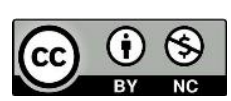

Published articles are freely available to users under the terms of Creative Commons Attribution - NonCommercial 4.0 International Public License, as currently displayed at here (the "CC BY - NC"). 


\title{
Research on Engineering Structures \& Materials
}

journal homepage: http://jresm.org

Editorial Note

\section{A view on how to mitigate earthquake damages in Turkey from a civil engineering perspective}

\author{
Hayri Baytan Ozmen
}

Department of Civil Engineering, Usak University, Usak, Turkey

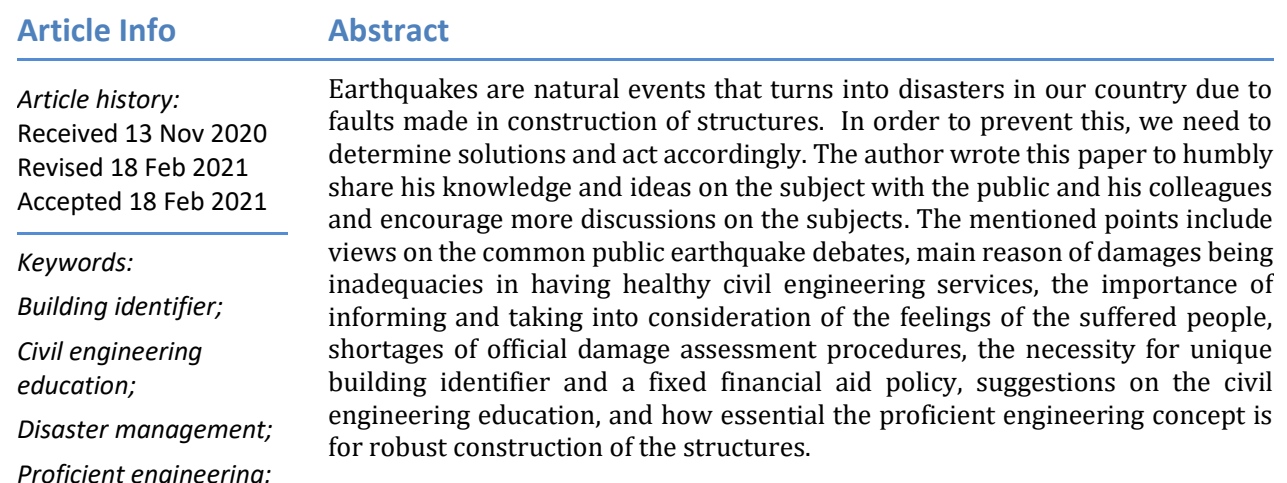

Proficient engineering;

(C) 2021 MIM Research Group. All rights reserved.

\section{Introduction}

Turkey, especially in the last two decades, has experienced enormous loss of life and property due to the medium and large scale earthquake that caused seismic damage[1,2]. As a result of the number of damaged buildings and casualties, attention has been focused on the insufficient performance of the structures and the reduction of earthquake damages. The interest in the subject has been renewed with the Aegean Earthquake of October 30, 2020, in which 116 deaths, 1034 injuries and various damages were suffered. Especially, this latest event, in addition to the many resembling others, has initiated the author to contribute to the recent discussions on measures to mitigate seismic damage by sharing his knowledge and evaluations on the subject.

The author has been conducting academic and hands-on studies on seismic evaluation and strengthening of the existing building stock for more than twenty years. He has made 11 research projects supported by national and international organizations (European Union, TUBITAK, AFAD, several universities) and dozens of scientific publications on the subject [3-13].

Apart from these, the author made detailed seismic strength assessment of approximately 200 buildings upon the requests of various public institutions and private parties. He has participated in strengthening studies for half of these. In addition, the author has been found in damage assessment of hundreds of other buildings affected by several earthquakes in Turkey [8, 14-16]. He carried out detailed studies in 225 buildings in Simav region after the 19 May 2011 Simav Earthquake by an invitation from AFAD to assess the feasibility of retrofitting $[17,18]$.

Corresponding author: baytan.ozmen@usak.edu.tr

orcid.org/0000-0001-6750-8632

DOI: http://dx.doi.org/10.17515/resm2020.231ea1113ed

Res. Eng. Struct. Mat. Vol. 7 Iss. 1 (2021) 1-11 
Working on the subject for different levels, having the opportunity to see the many aspects of the matter and being an academician enforces the author to express his thoughts. Author does not claim that the below given ideas are all correct and best versions. He just wants to contribute the discussions to achieve better solutions. The humble views of the author based on his experiences are given below:

\section{Public discussions on earthquakes}

In our country, although it is off the agenda once in a while, the issue of earthquakes is discussed intensely from time to time due to its frequent occurrence. These discussions focus on when and how large the earthquake will be rather than what we can do against earthquakes, as if we are desperate against them. There are extensive discussions in the press about the magnitude of earthquakes, the type and length of the fault, and where and how long are the faults. Many people in our country has become familiar with many geological terms, and this topic has become one of the daily talks. However, it should be evaluated how much debate has been made about what should be done to reduce earthquake damages and how much we are trying to raise public awareness.

The 2011 Van earthquakes are informative examples in terms of the proximity to the fault and the benefits of earthquake magnitude discussions. The epicenter of the 23 October 2011 earthquake is closer to Van than to Erciş. However, much more destruction took place in Erçiş. Muradiye, which is almost the same distance as Erciş from the epicenter of this earthquake and with resembling soil conditions, did not have similar destruction [19]. The earthquake of 23 October 2011 had a 7.2 magnitude, and the 9 November 2011 earthquake was 5.6 magnitude event. The distances of both earthquakes to the center of Van are not very different from each other. However, the 5.6 magnitude earthquake caused 4-5 times more collapse in Van than the first earthquake. It can be said that the structures damaged in the first earthquake collapsed in the second earthquake. However, there are many indications that the effects of the lower magnitude second earthquake in Van are greater [20].

When scientific studies and past earthquakes are examined, it is seen that the magnitude alone is not enough to explain the damaging nature of the earthquake. More than twenty parameters can be counted besides the magnitude related to the evaluation of the destructiveness of earthquakes[21-23]. Therefore, the discussions on "the magnitude of the earthquake will be this" and "the fault here will be broken at this length" are not as useful and primary information as they appear in the public. The provisions in earthquake regulations, if implemented, are in a position to ensure the survival of buildings in almost every earthquake that may occur in our country. Therefore, the issue is not to predict where and how big earthquakes will occur in the country in the future, but to ensure that earthquake regulations are implemented throughout the country.

\section{Perceptions on reasons of damage}

Unfortunately, the level of awareness regarding the issue is still very low in our country, which has suffered greatly due to the earthquakes. In the public debate, earthquake damages are still attributed to reasons such as low concrete strength, unwashed sand and high number of floors. These are of course important and constitute some of the sources of damage. However, bringing only these issues to the public attention prevents a complete solution and causes a useless consumption of the public energy. Though, common application errors such as reinforcement detailing, insufficient use of lateral reinforcement, faults in manufacture of beam-column joints, deficiencies in lateral load carrying system are among the important causes of damages. 
For example, a building with ready-mixed and good strength concrete, built in Erciş in 2011 is severely damaged. The reason for this damage is the use of insufficient lateral reinforcement in the structure, that is, failure to pay attention to engineering principles. There are also design errors related to shear wall locations in the same building [16]. The fact that the errors are attributed to only a few reasons mentioned above constitute an obstacle in creating public opinion and making regulations about the importance of adequate engineering services and the problems related to the training of engineers.

\section{Disaster management}

One of the first and most important studies after the earthquake is the determination of the damage status of the buildings. This issue came to the fore a lot in the public after the collapse of Bayram Hotel in 9 November 2011 Van Earthquake. As a result of confusing the damage assessment study conducted right after the earthquake with a general seismic assessment, the personnel who determined the damage state were criticized. In fact, that study was not an evaluation of the seismic performance of the structures and their behavior in future earthquakes, but an examination of the damage they have received in the past earthquake. Since the seismic assessment of the structure is a very detailed and time-consuming study, it is not possible to do it for an entire city after an earthquake. As an example, for an average building, it is normal for just gathering information process to take at least half a day in the building with a team of 7-8 people. In addition, with computer modeling and performance analysis, it is normal for the required time to be several days. Therefore, it is wrong to expect such an assessment from the damage assessment personnel right after an earthquake.

However, it can be said that there are some aspects that require improvement in postearthquake damage assessment studies:

- Assessment results vary and similar damages can be given different degrees of damage by different teams.

- Important differences can be seen between preliminary damage assessment results and final damage assessment results. In preliminary damage determination, a "severely damaged" structure can be turned into "light damage" by definitive detection or vice versa.

- The negligence of the technical staff who perform damage assessment as a burden and the desire to complete it as soon as possible, negatively affects the effective and efficient work.

These problems make things difficult in all other steps by reducing the public's trust and belief in public authority. It may be helpful to focus on some issues to make damage assessment studies healthier.

\subsection{Damage assessment in terms of safety and financial aspects}

Two questions are tried to be answered simultaneously while determining the damage state of the buildings: whether there is heavy damage in the building that will prevent the continuous occupation and to determine the cost level required to repair the damage in the building for possible financial assistance and credit. However, trying to answer these two questions with a single damage level causes problems. For example, in case of widespread wall damage, it may be necessary to increase the level of damage in order to increase the credit/assistance to be given, as the cost of repairing the building will increase. However, structurally, this is not a priority affecting safety. In addition, the fact that significant damage has occurred in a column of the building due to local construction errors seriously endangers the safety of the occupants. However, the repair of the damage may involve low costs due to its local nature. As in these examples, some personnel may 
choose to determine the degree of damage according to the extent of the destruction and some personnel according to its significance. Both approaches have justified reasons. For this reason, the author thinks that it will be useful to determine two separate damage level: one indicating the safety status of the building and the other for amount of credit/financial aid to be given.

In addition, it is necessary to consider damage assessment separately on the basis of flats and whole buildings. In fact, it is possible to experience significant wall damage in an apartment located on the ground floor of a building. In this case, significant repair costs will be incurred for this apartment. However, it is possible that no wall and bearing element damage could be found in an apartment on the upper floors of the same building. If we talk about the safety damage status as a reverse situation; in case of severe damage to the columns on the ground floor of the building, it is clear that although there is no damage in the upper floor apartments, the safety damage situation in those apartments should be evaluated as heavy.

The points in the above two paragraphs indicate how complex damage assessment is and why the damage status of structures can change significantly. Damage detection is a parameter that can be handled from four different points of view as the building and apartment level and its economic and safety aspects. It is natural that technical personnel who try to answer all four of these aspects with a single value have difficulties.

\subsection{Evaluation of damage status}

The engineers who examine the building may have different opinions about the safety level with regard to the widespread and low and the local and severe level of damage. The fact that people have different engineering views also causes different damage assessment results. By eliminating this kind of subjectivity, certain criteria can be defined for objective damage assessment and all decisions can be made accordingly. The staff can make a determination according to the answers to the questions in the forms they have. If the damage status of the building is determined as a result of a flow chart or scoring prepared according to the answers of certain questions, it will be ensured that all teams reach the same conclusion for the same damage case. Of course, it is important that the number and level of detail of these questions are minimum, taking into account the limited sources of time and labor. However, considering that the structures will not always have the same conditions, it may be inconvenient that the results of these forms are completely binding. In addition to the questions in the form, it may be important to reflect the engineers' specific views on the building. Ensuring that the damage assessment results are objective and independent of personnel, will be beneficial in terms of establishing the trust of the citizens and obtaining healthy damage assessment results.

It is also important to train relevant personnel in order to reduce different and unhealthy damage assessment results. Since engineering education is mostly aimed at new building design, training on these issues is not provided at a sufficient level as a standard. For this reason, the personnel making damage assessment should have received a separate training on this issue.

\subsection{Approach to damaged building owners}

Another important feature of the personnel who detects the building damage is conducting the first encounter of the state with citizens who experienced the earthquake. In this respect, it is an important step in showing that the state is interested in them. The author conducted a study on whether moderately damaged buildings in Simav district can be retrofitted after the earthquake of 19 May 2011 [11]. During this study, a survey process requiring 4-5 hours was carried out for each building, including taking core samples and detection of reinforcements in the ground floor. During these procedures, a building owner 
said, "You spent so much time and effort. From now on, we will accept whatever you say about the building.". Then, he said the he did not believe the previous damage assessment result as it took only 15 minutes of the previous personnel visited the building.

Citizens generally have a perception that building damage assessment is not done with sufficient care. Due to this understanding, citizens object to public authority at every stage of the administrative and legal procedures. In order to eliminate this negativity and for citizens to cooperate better with the state, it is important for the officials to inform the citizen in the damage assessment process, to explain how the decision was made, even if it was very brief. Regarding damage assessment decisions, besides technical training, providing psychological training to the personnel on this subject may also be considered. This proposal can be seen as a situation that will increase the burden of the personnel who work devotedly under limited resources. However, it is thought that it will be beneficial in terms of reducing the problems that may be experienced in the future.

Likewise, it is important to inform citizens about how the preliminary damage assessment study is carried out. It should be explained that the damage determination is a practice that is performed visually and takes a short time in nature. For this purpose, using the press or a brochure distributed by related staff explaining the procedures can be considered.

Another reason for the objection of the citizens to the damage assessment results is that the damage they have seen and the situation reported by the personnel do not match. It is possible to hear complaints such as "A little damage to my house was given a greater damage while there was so much damage to the house of another person" or vice versa. It has been observed that the reason for this is that the wall damage, which usually covers a larger area, is more credited by the citizens. Buildings with more wall damage are regarded as heavily damaged, and the cracks, which are thought to be at a smaller level, in the structural system elements such as columns and beams are not taken into consideration. It may also be considered that such information can be passed on to citizens by means such as the above mentioned brochure.

\subsection{Financial assistance policy to the damaged building owners}

One of the reasons for the lack of adequate dialogue with citizens by technical staff is that citizens try to pressure technical staff about the damage status. Some citizens try to increase the damage status in order to get more financial aid, some try to reduce the damage status in order not to spend money to retrofit their building. This issue stems from the fact that citizens do not fully know the aid and credit policy of the state and a fixed policy has not been implemented on this issue for a long time. In the past years, the monetary aids made after earthquakes and their dependence on the damage limit cause citizens to try to increase the damage status. For example, in the Simav earthquake, a citizen ensured that his slightly damaged structure was converted to moderately damaged, with the expectation that more financial aid would be given. However, as it is concluded that the 3-storey masonry structure cannot be strengthened in the subsequent evaluation, he is in danger of losing his building. However, in case of slight damage, it would have been possible that this result would not have occurred as per the legislation. As in any other uncertainty, the fact that the state's aid/credit policy is not fixed causes citizens to try to affect the damage assessment. In this respect, to whom and how the loans/aids will be given should be set forth as a transparent and unchangeable policy.

Especially after DASK insurance, there have been significant developments in the aid/loan policy and the uncertainty has largely disappeared. However, since this issue is not sufficiently known by the citizens, certain demands may still arise regarding the damage assessment result. Telling the citizen that each damage assessment result has positive and negative aspects and that the best way is to act according to the result of the technical 
examination of the building, will also help to overcome such problems. At this point, informing the citizens again comes to the agenda.

\section{Approach to the people suffered by the earthquake}

As mentioned in the section on damage assessment above, the psychological state of people who have experienced an earthquake is naturally bad and the approach to these people is important. Psychology training should also be considered for all the government personnel working in the earthquake zone. With the training to be provided, it is possible that the staff can come to the fore as an auxiliary element in terms of more effective communication and easier guidance of the public. This will prevent many future problems that may arise.

\subsection{Morale status of the people in the earthquake zone}

As mentioned in the previous section, the morale of the people in the region where the earthquake was experienced is low and this is the source of many problems. For example, after the 23 October 2011 Van earthquake, many citizens in Erciş, whose houses were not damaged at all, did not enter their homes for a long time due to fear. As statistics show, buildings collapsed and heavily damaged after many earthquakes are around $10 \%$ of the total number of buildings. However, with the remaining $90 \%$ not entering their buildings, the need for accommodation, food, etc. in the earthquake zone increases roughly 10 times. It is not an easy task to meet the need for shelter for a large city all at once. The necessity, economy, benefit/loss status of aid institutions to be able to fulfill such a request are a separate debate subject, but the considerations that started about the shortage of tents after the Van earthquake are an indication of this situation. This phenomenon is an example of the importance of managing the morale of the people after a disaster.

As the author follows in the press, various entertaining activities for children in the earthquake zone are good examples of services that can be done on the subject. Expecting adults to participate in such activities after the earthquake may not be expected and perhaps not appropriate in terms of morale. But doing these kinds of activities with children is beneficial for their parents to be positively affected.

Although such activities are important, the most important factor that can affect the morale of the people is that the state takes care of them and efforts are made to solve their problems. Of course, it is impossible for people who have experienced an earthquake to be fully satisfied, but it is also important to reduce the degree of dissatisfaction.

Press organizations have a great impact on this issue. In order to attract attention, mostly bad news regarding extreme cases takes place in the press. Although these news are beneficial in terms of raising the motivation to get help from the rest of the country, they negatively affect the morale of the people and the normal order of life in the earthquake region. Press organizations can be asked for help to include positive news especially in the local papers.

\section{Unique building identity number}

In many processes such as damage detection and gathering information about them, buildings must have a permanent "marker". However, in practice, many difficulties are encountered in identification of the buildings. For example, in the process of collecting information from the building, sometimes all and sometimes some of the information such as the names of the occupants or addresses and plot of the building are used. However, problems are encountered as the information of the same buildings is tried to be accessed in different institutions such as the municipality and public works. The property owners and residents of the buildings, most of which are over 20-30 years old, have mostly changed during this period. There are also differences in address information due to the 
change of street and neighborhood titles. The same is true for block and plot numbers. Block numbers change over time for different reasons, and plot numbers can change due to the merging and separation processes.

As a result of this situation, it is not possible to establish contact between the information collected from the field and the information held by public institutions. This situation may cause significant weaknesses in a subject where time is very important such as disaster management operations after an earthquake. For example, in the seismic assessment study conducted by the authors in the Simav district after the earthquake of 19 May 2011, significant time had to be spent on this subject. The information in the building files obtained from the municipality was compared with the individual damage assessment results, and the building information was partially combined. Since the mentioned study covers 225 buildings, it was possible to realize the process. However, it is clear that the problem will become insoluble when a study needs to be carried out on tens of thousands of buildings after an earthquake in big cities.

In order to overcome this problem, the author recommends using an "identification number" for each building plot. This number should be given for new plots with the formation of the plot and should not be changed under any circumstances. A unit in this identification number can be reserved for subdivision operation. In the unallocated plot, this value will be "0". In case of subdivision, this value can be increased by 1-9 for each new plot. Thus, the immutability of the identification number can be achieved. Similar approach can be made for other situations requiring change, if any. Last 2 digits are of the ID number can be reserved for flats in the building. Thus, just like for citizenship number for persons an unchangeable and unique identifier will be created for flats and buildings.

For existing buildings, these values can be assigned by the municipalities, so that all structures can have this unique marker. Thus, the information from all different institutions working on buildings can be collected in a common pool. In this way, significant labor and time will be saved in post-disaster management studies.

\section{Earthquake resistant construction of buildings}

Earthquakes have turned into disasters due to mistakes made for 20-30 years before it happens. Faults made in 30 years cannot be solved in 5-10 days. Of course, the main point to solve this problem is that the structures should be built earthquake resistant before the earthquake. No post-earthquake study can be considered as effective as building earthquake-resistant structures. Unfortunately, the scenes after the earthquakes in our country reveal that we are not at a sufficient level in this regard. The presence of such high number of damaged buildings after the earthquakes shows that many procedures and people have faults in construction of the building, from workers to engineers, contractors and owners. Issues such as the regulation of the building inspection system, the use of quality materials in buildings, etc. are much discussed in public. Although the author admits that these points are quite important, he wants to draw attention to the issues that he thinks have not been discussed enough, rather than addressing the issues that have been repeated in many occasions.

First of all, the primary reason for the collapse of the structures is not that the structures are made with low strength concrete, un-ribbed reinforcement, sea sand, and lack of shear walls. As partly mentioned above, there are structures that have totally collapsed in Erciss in the earthquake of 23 October 2011 despite being manufactured with high-strength concrete and ribbed steel. Next to these, there are also two-storey mudbrick structures built in accordance with engineering principles and not seriously damaged at all during the earthquake. The primary cause of the damage is structures that have not received adequate 
engineering services. For this reason, some suggestions will be presented regarding the development of civil engineering service in our country:

\subsection{Proficient engineering concept}

Civil engineering is perhaps a branch of engineering where proficient engineering concept is most needed among all others. Because it does not include an auto-control like many other engineering fields. For example, when an electronic engineer is asked to design a circuit, if the circuit in question works, the engineer is successful, if not, the engineer is unsuccessful. In this case, the engineer who cannot make the desired circuit has to improve himself. However, in civil engineering, testing of the work takes place in every 30-40 years by an earthquake for most cases and by this time it is too late. In other words, there is no auto-control in civil engineering for the person to be competent and to improve himself with advancements in the field.

On the contrary, there is a pressure on the civil engineers to relax the rules of earthquake resistant construction. Since being afraid is the work of knowledgeable people, good civil engineers are aware of the danger. However, nobody in the constructions business likes them. Architects are not happy because their design is interfered with when they talk about the deficiencies in the design, the contractor will not be happy because more materials and workmanship is required, the owner will not be satisfied because the house may not be exactly what he wants or it will be more expensive, workers are not satisfied because it is harder to do what they want, and nobody wants to work with this engineers. In this case, although the good engineer has worked harder and improved himself, he is criticized from all parties involved. Since this situation should not be allowed, a system that will protect the engineer who does his job well is necessary. This can be done with expert or proficient engineering concept.

According to the author, engineers should be tested every 5 years and according to the fields they work in. Fields should be seperated such as structural engineering, management, construction engineering, geotechnical engineering, hydraulic engineering, etc. Only the ones who are successful in the related exams, can have the license to conduct the engineering services. There should be at least 3 classes such as A, B, C instead of being directly successful or unsuccessful. Those who fall below a certain score should not have license, and others should be authorized for jobs in size according to their grade. Thus, it may be possible to increase the motivation of engineers to have a higher degree. Everyone should have a field of specialization (or if they are successful in the exams, they can have more than one), and accordingly, they should not be accepted as an authorized person in every job that comes their way. Although similar legal regulations have been discussed for many years, they have not been implemented.

Starting with 2008, it was imposed that the engineers who design buildings had to collect a certain score each year by participating in activities such as various courses and scientific meetings. During this period, the author tried to contribute to this process by teaching in some courses and by making scientific presentations. It has been observed that the participating engineers were not satisfied at first because it took their time, but afterwards they were generally satisfied in terms of increasing their knowledge and becoming more capable. However, with the relaxation of the conditions later, this rule became dysfunctional and a very useful and important step in the training of engineers was lost.

\subsection{Re-organization of civil engineering education}

Civil engineering is a branch of engineering that covers a wide range of topics. Civil engineers work in many fields from computing the durations of traffic lights to water network construction, from determination of building site conditions to design of dams, from highways to construction of skyscrapers. Naturally, not every engineer can be 
expected to have in-depth knowledge of each of these subjects. Some of them have very distinct characteristics to each other.

Although civil engineering education varies in every university, the major divisions consist of Structural mechanics, Materials, Construction Management, Mechanics, Hydraulics, Transportation and Geotechnics. Among these departments, there are branches that are closely related to all other branches such as material, mechanics and geotechnics, as well as branches that can be seen far from each other such as structural mechanics and transportation, structural mechanics and hydraulics. Civil engineering, like all engineering branches, is a 4-year department and during this period, all the information about these departments, some related and some unrelated, is given to all students.

However, if proficient engineering is put into practice for the engineers to specialize and become expert in certain branches, as stated above, there will be a discrepancy between the goal and the content of the education. For example, for a student who wants to specialize in building design and construction, the courses regarding the use of water resources, designing traffic lights, etc will be useless. In this case, it will be waste of the resources of both the student and the university.

In fact, this issue, which has become more visible with the emergence of the concept of proficient engineering, is among the problems of civil engineering education. There is little or no other profession with such widespread coverage. In order to solve this problem, dividing civil engineering into other engineering branches and opening different departments for each of them is a difficult and perhaps not a necessary process to carry out in the short term. Instead, it may be a solution to educate the students in divisions that are determined when they begin the university education or after a two-year program of common courses. The related division should be included in the diplomas given at the end of the education and the use of signature rights should be arranged accordingly. In this way, it will be possible to train more competent engineers in each specialization.

\section{Summary \& conclusions}

Earthquakes are natural events that turns into disasters in our country due to faults made in construction of structures. In order to prevent this, we need to determine solutions and act accordingly. The author wrote this paper to humbly share his knowledge and ideas on the subject with the public and his colleagues. The mentioned points may be summarized as follows:

- When discussing about earthquake damages, much of the public energy is wasted on considerations regarding the locations of the faults, timing and magnitude of the next earthquake. However, scientific experiences show that even if we know when, where and how big the next earthquake will be, it has little impact on the mitigation of seismic damage.

- Reasons of building damage are reduced to a few simple points such as low strength concrete, use of unwashed sand and un-ribbed steel, etc. However, the main problem is the insufficient engineering services. Attributing the errors to only a few other reasons constitute an obstacle in creating public opinion and making regulations about the importance of getting adequate engineering service.

- We also have problems on disaster management and controlling the situation after an earthquake. We should take into account the feelings of the people more and inform them more to have their collaboration.

- Official damage assessment after the earthquake should be handled differently in financial-safety aspects and flat-building level. The damage status evaluations 
should be independent of the evaluator and more definitive for the property owners.

- Financial aid and loan policies should be clear, fixed and invariable for different earthquakes.

- Morale status in a post-earthquake region may affects the amount of required resources to shelter and organize the suffered people.

- Just like the people, we need unique identity numbers for the buildings to quickly and accurately combine the information from different sources after or before an earthquake.

- Unquestionably, the main solution for preventing earthquake damages is based on building earthquake resistant structures. Civil engineers are the key elements to achieve this goal. Some improvements should be made in civil engineering education. Additionally, proficient engineering concept should be included in related laws and regulations as soon as possible to have healthy civil engineering service.

There is no claim that each of the ideas here is the most correct. We can reach the best solution by sharing ideas and discussing on the matter. Some of the issues mentioned can be seen as difficult to implement and some of them as obvious solutions. However, the author aims to contribute to the formation of public opinion by encouraging the discussions.

\section{References}

[1] Ozmen HB, Yilmaz H, Yildiz H. An acceleration record set for different frequency content, amplitude and site classes. Res Eng Struct Mater. 2019; 5(3). https://doi.org/10.17515/resm2019.116ea0209ds

[2] Ozmen HB, Inel M, Meral E, Bucakli M. Vulnerability of low and mid-rise reinforced concrete buildings in Turkey. In: 14th European conference on earthquake engineering. Ohrid, Macedonia; 2010.

[3] Modeling Non-Linear Behavior of Reinforced Concrete Members, TUBITAK, 105M024, 2005-2008.

[4] Effect of Recent Earthquake Code Modifications on the Strength and Ductility of Reinforced Concrete Public Buildings, Pamukkale University Scientific Research Unit (PAUBAP), 2006MHF007, 2006-2008.

[5] Effect of Glass FRP Reinforcement Locations on Flexural Strength and Ductility of Reinforced Concrete Structural Members, Ușak University Scientific Research Unit (UBAP), 2016/TP014, 2016- 2020.

[6] Evaluation of the Factors Affecting Seismic Performance of Mid and Low-Rise Reinforced Concrete Buildings, TUBITAK, 107M569, 2008-2011.

[7] Determination of the Structural Properties of the Existing Reinforced Concrete Buildings, Pamukkale University Scientific Research Unit (PAUBAP), 2008FBE005, 2008-2011.

[8] 2007 October Çameli Earthquake Damaged Masonry Building Inventory, TUBITAK, 108M408, 2008-2009.

[9] Improving the Quality of Suburban Building Stock, (European Cooperation in the Field of Scientific and Technical Research) COST Project TU 701, 2008-2012.

[10] Earthquake Science School, TUBITAK Science and Society Project, 110B072, 2010 2011. 
[11] Evaluation of the Feasibility of Retrofitting the Moderately Damaged Buildings in and around Simav County after 2011 May Simav Earthquake, Prime Ministry Disaster \& Emergency Management Presidency (AFAD), 2011-2011.

[12] Investigation of the Relation between Seismic Damage and Characteristics of the Earthquake Records, Pamukkale University Scientific Research Unit (PAUBAP), 2011BSP024, 2011- 2013.

[13] Change of Earthquake Ground Motions Depending on Soil Properties, TUBITAK, 215M357, 2015-2019.

[14] Kumsar H, Özkul M, İnel M, Hançer M, Tama YS, Ozmen HB, et al. 29 october 2007 çameli earthquake pre-examination report. Denizli, Turkey; 2007.

[15] Inel M, Ozmen HB, Akyol E. Observations on the building damages after 19 May 2011 Simav (Turkey) earthquake. Bull Earthq Eng. 2013; 11(1). https://doi.org/10.1007/s10518-012-9414-3

[16] Ozmen HB, Inel M, Cayci BT. 23 October and 9 November 2011 Van Earthquakes Structural Damage Assessment Report. Denizli, Turkey; 2011.

[17] Inel M, Un H, Ozmen HB, Akyol E, Cayci BT OG. Investigation of the feasibility of retrofitting the moderately damaged buildings in Simav region and surroundings. Denizli, Turkey.

[18] Ozmen HB, Inel M, Akyol E, Cayci BT, Un H. Evaluations on the relation of RC building damages with structural parameters after May 19, 2011 Simav (Turkey) earthquake. Nat Hazards. 2014; 71(1). https://doi.org/10.1007/s11069-013-0900-y

[19] Ozmen HB, Inel M, Cayci BT. Engineering implications of the RC building damages after 2011 van earthquakes. Earthq Struct. 2013; 5(3). https://doi.org/10.12989/eas.2013.5.3.297

[20] Disaster and Emergency Management Authority (AFAD). Van Earthquake Report. 2011.

[21] Kramer SL. Geotechnical Earthquake Engineering. Prentice-Hall, Inc. 1996. 653 p.

[22] Ozmen HB, Inel M. Damage potential of earthquake records for RC building stock. Earthq Struct. 2016; 10(6). https://doi.org/10.12989/eas.2016.10.6.1315

[23] Ozmen HB. Developing hybrid parameters for measuring damage potential of earthquake records: case for RC building stock. Bull Earthq Eng. 2017; 15(7). https://doi.org/10.1007/s10518-016-0080-8 